\title{
Molecular and Genetic Aspects of Diabetic Retinopathy Diagnosis
}

\author{
A.G. Iskhakova ${ }^{1}$, A.N. Toropovsky², A.V. Zolotarev ${ }^{1}$, O.N. Pavlova ${ }^{1,2,3^{*}}$ and M.V. \\ Komarova $^{1,4}$
}

\author{
${ }^{1}$ Samara State Medical University, Samara, Russia \\ ${ }^{2}$ TestGen LLC, Ulyanovsk, 432072, Russia \\ ${ }^{3}$ Samara State Transport University, Samara, Russia \\ ${ }^{4}$ Samara National Research University named after Academician S.P. Korolev, Samara, Russia \\ *Corresponding author. Email: casiopeya13@mail.ru
}

\begin{abstract}
One of the many complications of endocrine disease such as diabetes is diabetic retinopathy. As a rule, the severity of retinopathy depends on the duration of diabetes mellitus, blood glucose concentration and blood pressure level. The aim of the study was to investigate the influence of genetic factors on the risk of diabetic retinopathy and to improve the prognosis of this pathology using mathematical modeling. A total of 475 patients participated in the study. The authors of the study concluded that the polymorphic loci of VEGF rs2010963, AKR1B1 rs759853, ITGA2 rs2910964, ADRB3 rs4994, APOE rs7412, APOE 429358 genes, considered independently of each other, were not associated with the development of diabetic retinopathy in the studied group of type II diabetic patients. However, consideration of complex interallelic interactions of VEGF, AKR1B1 and APOE genes allows us to identify unfavorable combinations of genotypes. Diabetes mellitus and glycemia history increase the likelihood of diabetic retinopathy. The proposed combination of genes in combination with biochemical indices increases the prognostic significance of the developed test system.
\end{abstract}

Keywords: endocrine disease, diabetic retinopathy, genetic factors, mathematical modeling

\section{INTRODUCTION}

One of the many complications of an endocrine disease such as diabetes is diabetic retinopathy (DR). It is a lesion of the retinal vessels, which is the cause of visual disability in patients in $80-90 \%$ of cases [1].

Diabetic retinopathy is the main cause of blindness in the able-bodied population of developed countries. It has been found that patients with diabetes mellitus (DM) develop vision loss or visual impairment 25 times more often than the average in the population, and the longer the "experience" of DM, the higher the risk of DR. According to numerous literature data, pathological changes in the retina are detected in about $80 \%$ of patients with diabetes for 10 years or more $[2,3]$.

The greatest threat to vision loss is proliferative DR, which is present in $50 \%$ of patients with type 1 diabetes for 20 years or more. In type 2 diabetes that amounts to 90-95\% of all cases of this disease due to late diagnosis, the signs of DR are detected in 15-30\% of cases at the moment of diabetes diagnosis, in 10 years in 50-60\%, and after 30 years - in more than $90 \%$ of patients $[4,5]$.

Currently, a distinction is made between nonproliferative, preproliferative, and proliferative DR. The nonproliferative form is essentially the initial stage of DR and is characterized by occlusion and increased permeability of small retinal vessels. The preproliferative retinopathy stage is characterized by venous abnormalities (crispness, tortuosity, presence of loops, etc.), a large number of solid and "cotta-like" exudates, intraretinal microvascular abnormalities, large retinal hemorrhages. If this condition is not treated, proliferative DR develops, when capillary occlusion leads to extensive zones of ischemia with the formation 
of microaneurysms and retinal blood supply disorders. Retinal changes at this stage proceed in two ways: formation of newly formed vessels or connective tissue overgrowth $[6,7]$.

As a rule, the severity of retinopathy depends on the duration of diabetes mellitus, blood glucose concentration and blood pressure level.

Total vision loss is most often associated with the development of a proliferative process: vitreous hemorrhage, retinal detachment and the development of neovascular glaucoma, which occurs due to the blocking of the outflow of intraocular fluid by newly formed vessels and leads to an uncontrollable increase in intraocular pressure. In order to avoid the above complications, it is extremely important to diagnose the development of this disease as early as possible.

The aim of the study was to investigate the influence of genetic factors on the risk of diabetic retinopathy and to improve the effectiveness of prediction of the development of this pathology using mathematical modeling.

Study objectives are to establish the distribution of alleles and genotypes of a complex of polymorphic markers of candidate genes for the development of diabetic retinopathy: vascular endothelial growth factor (VEGF), AKR1B1, ADRB3, ITGA2, APOE in groups of patients with type 2 diabetes; to assess the association of polymorphic markers of these candidate genes with the risk of diabetic retinopathy in type 2 diabetes; to determine the relationship between genetic polymorphisms associated with diabetic retinopathy and variants of the clinical course of the disease.

The study was performed at the Samara Regional Clinical Ophthalmological Hospital named after T.I. Yeroshevsky, also at TestGen LLC and Genext LLC (Ulyanovsk), where DNA extraction and analysis of polymorphic gene markers took place.

A total of 475 patients participated in the study: 79 men and 396 women who met the inclusion and exclusion criteria and gave written informational consent to participate in the scientific study. The age of the patients ranged from 24 to 89 years old.

No diabetic retinopathy was detected in 272 patients at the time of examination, 100 patients had nonproliferative diabetic retinopathy, 23 patients had preproliferative DR, and 80 patients had proliferative DR.

The objects of the study were venous blood samples obtained from patients with type 2 diabetes mellitus who underwent ophthalmological examination.

The detailed methodology of the study is given in our work published earlier [8].

Seven point mutations whose detection should reveal an increased risk of DR in diabetes mellitus were selected for the study: VEGF rs2010963, AKR1B1 rs759853, ITGA2 rs2910964, ADRB3 rs4994, ICAM1 rs 13306430, APOE rs7412, APOE 429358. Both APOE gene loci were analyzed together in statistical data processing. The final selection of candidate gene polymorphisms for inclusion in the test system for DR risk analysis was based on the results of technical and clinical tests according to the following criteria: the genetic polymorphisms included in the ready-made test system should have the highest possible association with diabetic retinopathy and allow ensuring diagnostic accuracy of the test system.

Statistical analysis of the obtained data was performed using IBM SPSS 21. Pearson chi-square test was used to compare the frequencies of genotypes with the presence of retinopathy. Multiple logistic regression was used to develop a prognostic model of retinopathy risk. Prediction quality was assessed using ROC-curves.

MDR method was used to identify combinations of genotypes for various genes associated with a greater or lesser risk of retinopathy [9].

The critical value of the significance level was taken as 0.05 .

\section{RESULTS}

The first stage of our study was the search for associations of DR with hereditary risk factors and analysis of conjugation tables between various polymorphic regions of candidate genes and the presence of diabetic retinopathy was performed. We found that for each of the genes considered, the distribution of genotypes in patients with and without diabetic retinopathy was statistically indistinguishable (all $\mathrm{p}>0.05$ ).

We examined the compliance of genotype frequencies with the Hardy-Weinberg equilibrium. For all AKR1B1 rs759853, ITGA2 rs2910964, ADRB3 rs4994, APOE rs7412, APOE 429358 genes, this equilibrium was observed. For the VEGF gene rs2010963, there was no Hardy-Weinberg equilibrium in patients either with or without diabetic retinopathy or among all patients examined. The lower by almost $10 \%$ than theoretically expected frequency of heterozygotes for the VEGF gene in the studied group of patients, in our opinion, may be related to non-random selection of genotypes during the formation of the studied groups of diabetic patients from the general population.

The absence of statistically significant relationships between individual genotypes in polymorphic gene segments determined the further search for intergenic interactions that could increase or conversely decrease the risks of retinopathy. To search for favorable and unfavorable gene combinations, we used the MDR method, which does not assume any genetic model and 
does not estimate any parameters, but only selects combinations of genes and genotypes most closely related to the outcome.

Initially, a combination of genotype distribution of polymorphic regions of VEGF rs2010963 and AKR1B1 rs759853 genes was isolated by the program (Fig. 1).

According to Figure 1, we found that the extreme variants: the two leftmost bars are combinations of homozygote for the rarer variant of AKR1B1 gene with heterozygote for the rarer variant of VEGF gene $(57 \%)$ or homozygote for VEGF gene $(50 \%)$ are present in patients with the presence of diabetic retinopathy. Conversely, DR rarely developed in carriers of "wild" variants of polymorphisms for two genes simultaneously: VEGF and AKR1B1 (rightmost bar, $30 \%$ of patients with DR). Low frequencies of diabetic retinopathy were also observed when two heterozygous variants of VEGF and AKR1B1 genes were combined simultaneously $(37 \%)$.

In evaluating the quality of this prognosis, the method was found to be $55.6 \%$ accurate, $59.6 \%$ sensitive, $52.6 \%$ specific, odds ratio 1.64 (1.13-2.36); $\mathrm{X}^{2}: 6.917(\mathrm{p}=0.0085) ; \mathrm{X}^{2}$ (Yates pop.) 6.437 $(\mathrm{p}=0.011) ;$ Kappa:0.12.

These characteristics are not sufficient, so we continued our prognostic search using a combination of the genotype distribution of polymorphic sites of three genes: VEGF rs2010963; AKR1B1 rs759853; APOE site rs7412 and site rs429358 (Fig. 2).

Since both APOE gene sites (rs7412 and rs429358) were considered together, we introduced coding for genotype combinations (Table 1).

In the APOE rs7412 gene site, the $\mathrm{C}$ allele is wildtype, more frequent. In the APOE rs7412 gene site, the $\mathrm{T}$ allele is wild-type, more frequent.

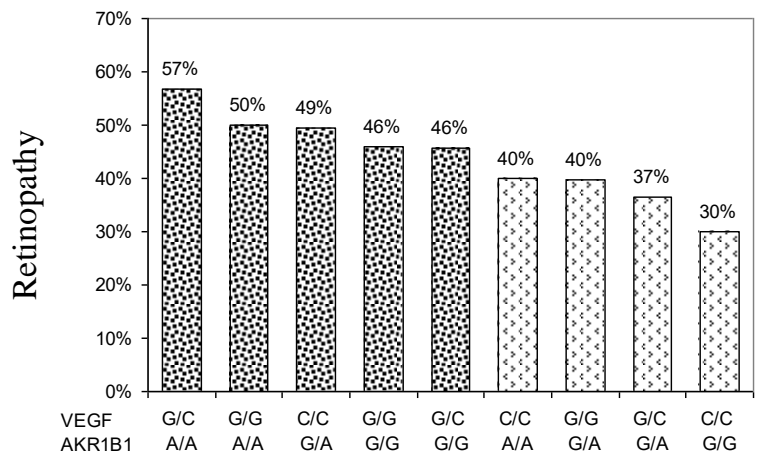

Figure 1. Proportion of patients with diabetic retinopathy with different genotypes according to polymorphic loci of VEGF rs2010963 and AKR1B1 rs759853 genes (dark shading indicates those classified as positive; light shading indicates negative)

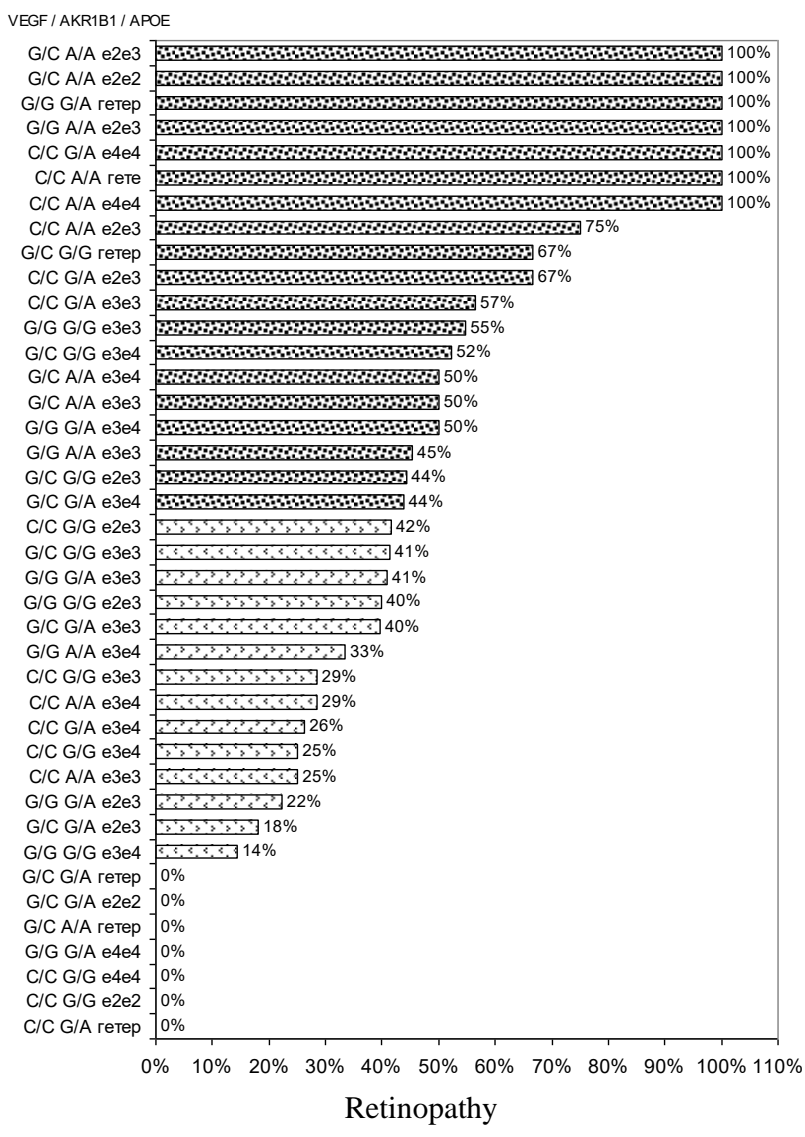

Figure 2. Proportion of patients with retinopathy (any stage) with different genotypes according to polymorphic loci of VEGF rs2010963 and AKR1B1 rs759853 and APOE genes (dark shading indicates those classified as positive; by light shading - as negative)

Table 1. Nucleotide labeling of the united sites of the APOE gene

\begin{tabular}{|l|l|l|}
\hline \multicolumn{2}{|l|}{ Nucleotide designation } \\
\hline APOE rs7412 & APOE rs429358 & APOE united \\
\hline T/T & T/T & e2e2 \\
\hline$C / T$ & $\mathrm{~T} / \mathrm{T}$ & $\mathrm{e} 2 \mathrm{e} 3$ \\
\hline C/C & $\mathrm{T} / \mathrm{T}$ & $\mathrm{e} 3 \mathrm{e} 3$ \\
\hline $\mathrm{C} / \mathrm{C}$ & $\mathrm{T} / \mathrm{C}$ & $\mathrm{e} 3 \mathrm{e} 4$ \\
\hline$C / C$ & $\mathrm{C} / \mathrm{C}$ & e4e4 \\
\hline$C / T$ & $\mathrm{~T} / \mathrm{C}$ & heterozygotes \\
\hline
\end{tabular}

According to Figure 2, some combinations of genotype sites of the three genes are found to determine $100 \%$ of the development of diabetic retinopathy:

1. combination of VEGF heterozygote with homozygote for the rare AKR1B1 and the combined APOE e2e3 gene;

2. combination of VEGF heterozygote with homozygote for rare type AKR1B1 and united APOE gene e2e2; 
3. combination of homozygote on rare type of VEGF gene with heterozygote of AKR1B1 gene and united APOE heterozygote;

4. combination of homozygote for wild-type VEGF gene with homozygote for rare AKR1B1 gene and united APOE e2e3 gene;

5. combination of homozygote for wild-type VEGF gene with heterozygote for AKR1B1 gene and united APOE gene e4e4;

6. combination of homozygote for wild-type VEGF gene with homozygote for rare type AKR1B1 and united APOE gene heterozygote;

7. combination of the wild-type homozygote of the VEGF gene with the rare-type homozygote of AKR1B1 and the pooled APOE gene e4e4.

Combinations of genotype sites of three genes determining the absence of diabetic retinopathy were also established:

1. combination of VEGF heterozygote with AKR1B1 heterozygote and combined APOE heterozygote gene;

2. combination of VEGF heterozygote with AKR1B1 heterozygote and APOE e2e2 united gene;

3. combination of VEGF heterozygote with AKR1B1 rare type homozygote and APOE heterozygote united gene;

4. combination of VEGF rare type homozygote with AKR1B1 heterozygote and APOE e4e4 united gene;

5. combination of homozygote for wild-type VEGF with homozygote for wild-type AKR1B1 and combined APOE e4e4 gene;

6. combination of VEGF wild-type homozygote with AKR1B1 wild-type homozygote and APOE e2e2 united gene;

7. combination of VEGF wild-type homozygote with AKR1B1 heterozygote and APOE heterozygote united gene.

In assessing the quality of this prediction, we found the method to be $62.0 \%$ accurate, $54.0 \%$ sensitive, and $68 \%$ specific, with an odds ratio of 2.52 (1.73-3.66); $\mathrm{X}^{2}$ : $23.6(\mathrm{p}=0.001) ; \mathrm{X}^{2}$ (Yates' exp.) $22.7(\mathrm{p}=0.001)$; Kappa:0.23.

We considered the obtained characteristics as insufficient and used multiple logistic regression with stepwise inclusion or exclusion of predictors (predictive variables) to further improve the risk prediction of diabetic retinopathy. Clinical and laboratory data of patients were considered as possible risk factors, among which the most significant ones in our opinion were: the blood glycated hemoglobin concentration, blood glucose concentration, and the length of diabetes.
We obtained three robust models that included combinations of genotypes developed by MDR (two models with a combination of three genotypes and one model with a combination of two genotypes). The duration of the diabetes mellitus and glycemic level was estimated either by glycated hemoglobin or by the glucose level (Table 2).

Possible risk factors such as age, body mass index, blood pressure, and lipid metabolism parameters were also among the potential predictors, but none were included in the final multivariate model.

For model 1, the prediction quality at threshold probability (cut off) $=0.4$ has sensitivity of $74 \%$, and specificity of $74 \%$. For model 2, sensitivity was $73 \%$, and specificity was $72 \%$. Model 3, taking into account the two genes, diabetes history, and glycated hemoglobin and blood glucose concentrations, had a sensitivity of $78 \%$, and specificity of $74 \%$.

Thus, additional consideration of glycated hemoglobin and blood glucose concentrations, as well as the duration of diabetes mellitus disease, in addition to the combination of unfavorable genotypes according to polymorphic gene segments, improves the accuracy of prediction of diabetic retinopathy development. In particular, the sensitivity of the method increased from $54 \%$ when predicting only genetic predisposition to $74 \%$ taking into account a complex of factors (genetic predisposition, hyperglycemia, duration of diabetes mellitus).

Of particular note is the fact that when using the classifier based on only two genes, the quality of prognosis was worse. Nevertheless, when using it in combination with other risk factors (length of diabetes mellitus, glucose and glycated hemoglobin concentration in blood), the obtained sensitivity and specificity increased significantly and even became higher than that in the model based on three genes. Compared to genetic prediction alone, both sensitivity (from 59.6 to $78.0 \%$ ) and specificity increased significantly from 52.6 to $74.0 \%$.

Undoubtedly, the main predictor is the experience of diabetes mellitus, but also genetic predisposition plays a statistically significant role. Perhaps it is the factors of heredity that influence the peculiarities of diabetes mellitus course and its clinical manifestations in the body as a whole.

To further assess the quality of the obtained logistic regression models and individual risk factors included in the models, we applied ROC-analysis.

The analysis of the first one using ROC-analysis is shown in Figure 3 and Table 3.

The presented graphs clearly show that each of the possible risk factors has a worse prognostic ability than 
the model including them. Model 1 has an AUC $=0.824$ (95\% confidence interval: $0.785-0.862$ ).
The analysis of the second logistic regression model with ROC analysis is shown in Figure 4 and Table 4.

Table 2. Multiple logistic regression models for assessing the development of DR with regard to risk factors

\begin{tabular}{|c|c|c|c|}
\hline Predictor & Regression coefficient, b & $\begin{array}{l}\text { Odds ratio } \\
\text { (95\% confidence interval) }\end{array}$ & $p$ \\
\hline \multicolumn{4}{|l|}{ Model 1} \\
\hline $\begin{array}{l}\text { Classification by } 3 \text { genes } \\
\text { gen1z - VEGF; gen3z - AKR1B1; gen7z - APOE }\end{array}$ & 0.99 & $2.70(1.71-4.27)$ & $<0.001$ \\
\hline Glycated hemoglobin, \% & 0.48 & $1.62(1.41-1.87)$ & $<0.001$ \\
\hline Diabetes rate, years & 0.11 & $1.11(1.08-1.15)$ & $<0.001$ \\
\hline Constant & -5.96 & - & $<0.001$ \\
\hline \multicolumn{4}{|l|}{ Model 2} \\
\hline $\begin{array}{l}\text { Classification by } 3 \text { genes } \\
\text { gen1z - VEGF; gen3z - AKR1B1; gen7z - APOE }\end{array}$ & 0.85 & $2.33(1.50-3.61)$ & $<0.001$ \\
\hline Glucose, mmol/l & 0.21 & $1.23(1.15-1.32)$ & $<0.001$ \\
\hline Diabetes duration, years & 0.12 & $1.12(1.09-1.16)$ & $<0.001$ \\
\hline Constant & -3.98 & - & $<0.001$ \\
\hline \multicolumn{4}{|l|}{ Model 3} \\
\hline Classifier by 2 gen1z - VEGF; gen3z - AKR1B1 & 0.48 & $1.61(1.03-2.51)$ & 0.035 \\
\hline Glucose & 0.08 & 1.09 (1.00-1.19) & 0.050 \\
\hline Glycated hemoglobin \% & 0.37 & $1.45(1.22-1.71)$ & $<0.001$ \\
\hline Diabetes duration, years & 0.11 & $1.11(1.08-1.15)$ & $<0.001$ \\
\hline Constant & -5.66 & - & $<0.001$ \\
\hline
\end{tabular}

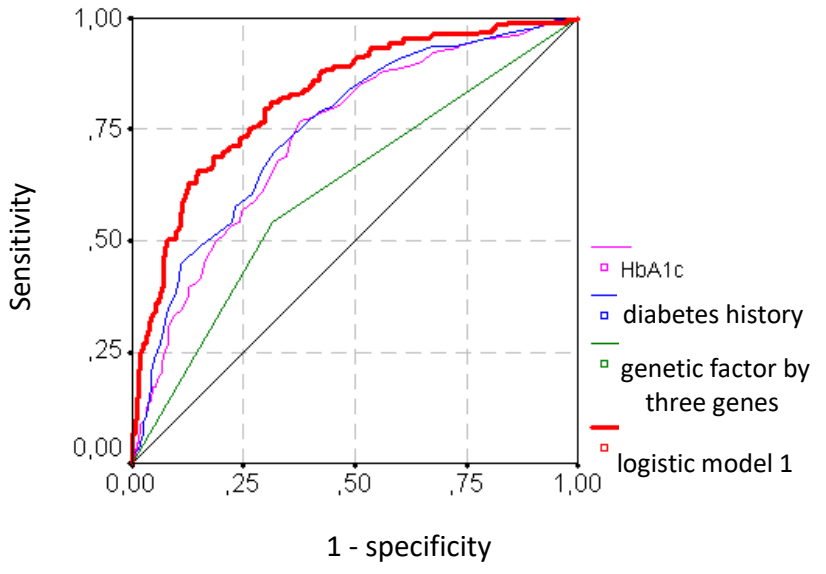

Figure 3. ROC analysis of the first logistic regression model

It is clear from the presented graphs that each of the possible risk factors also has worse prognostic ability than the model including them. Model 2 has an AUC $=0.812(95 \%$ CI: 0.773-0.850).
Table 3. ROC analysis of the first logistic regression model

\begin{tabular}{|c|c|c|c|c|c|}
\hline \multirow[t]{2}{*}{$\begin{array}{l}\text { Test Result } \\
\text { Variable(s) }\end{array}$} & \multirow[t]{2}{*}{ Area } & \multirow[t]{2}{*}{$\begin{array}{l}\text { Std. } \\
\text { Error(a) }\end{array}$} & \multirow[t]{2}{*}{$\begin{array}{l}\text { Asymptotic } \\
\text { Sig.(b) }\end{array}$} & \multicolumn{2}{|c|}{$\begin{array}{l}\text { Asymptotic } \\
95 \% \\
\text { Confidence } \\
\text { Interval }\end{array}$} \\
\hline & & & & $\begin{array}{l}\text { Lower } \\
\text { Bound }\end{array}$ & $\begin{array}{l}\text { Upper } \\
\text { Bound }\end{array}$ \\
\hline Logistic model 1 & 0.824 & 0.020 & $<0.001$ & 0.785 & 0.862 \\
\hline $\begin{array}{l}\text { Combination of } \\
3 \text { genotypes } \\
\text { (VEGF, AKR1B1, } \\
\text { APOE) }\end{array}$ & 0.614 & 0.027 & $<0.001$ & 0.562 & 0.667 \\
\hline Diabetes history & 0.752 & 0.023 & $<0.001$ & 0.708 & 0.797 \\
\hline $\begin{array}{l}\text { Glycated } \\
\text { hemoglobin \% }\end{array}$ & 0.734 & 0.023 & $<0.001$ & 0.688 & 0.78 \\
\hline
\end{tabular}




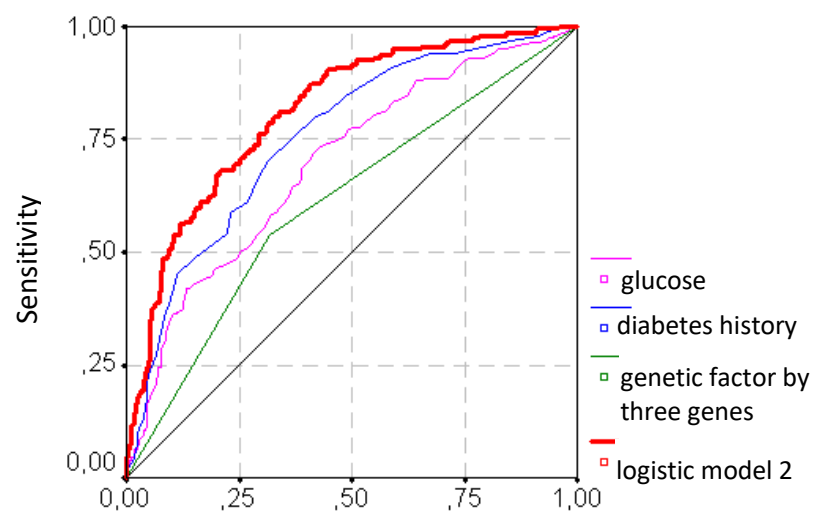

1 - specificity

Figure 4. ROC-analysis of the second logistic regression model

Table 4. ROC analysis of the second logistic regression model

\begin{tabular}{|c|c|c|c|c|c|}
\hline \multirow[t]{2}{*}{$\begin{array}{l}\text { Test Result } \\
\text { Variable(s) }\end{array}$} & \multirow[t]{2}{*}{ Area } & \multirow[t]{2}{*}{$\begin{array}{l}\text { Std. } \\
\text { Error(a) }\end{array}$} & \multirow{2}{*}{$\begin{array}{l}\text { Asymptotic } \\
\text { Sig.(b) }\end{array}$} & \multicolumn{2}{|c|}{$\begin{array}{l}\text { Asymptotic } \\
95 \% \\
\text { Confidence } \\
\text { Interval }\end{array}$} \\
\hline & & & & $\begin{array}{l}\text { Lower } \\
\text { Bound }\end{array}$ & $\begin{array}{l}\text { Upper } \\
\text { Bound }\end{array}$ \\
\hline $\begin{array}{l}\text { Logistic } \\
\text { model } 2\end{array}$ & 0.812 & 0.020 & $<0.001$ & 0.773 & 0.850 \\
\hline $\begin{array}{l}\text { Combination } \\
\text { of } 3 \text { genotypes } \\
\text { (VEGF, AKR1B1, } \\
\text { APOE) }\end{array}$ & 0.609 & 0.026 & $<0.001$ & 0.557 & 0.660 \\
\hline $\begin{array}{l}\text { Diabetes } \\
\text { history }\end{array}$ & 0.756 & 0.022 & $<0.001$ & 0.712 & 0.799 \\
\hline Glucose & 0.696 & 0.024 & $<0.001$ & 0.648 & 0.743 \\
\hline
\end{tabular}

The analysis of the third logistic regression model and ROC is shown in Figure 5 and Table 5.

When analyzing the third model, we found a similar trend: each of the possible risk factors also has worse prognostic ability than the model including them. Model 3 had an AUC of 0.814 (95\% confidence interval: 0.774-0.855).

Based on the above, we decided to take Model 3 as the basis, combining the two genotypes, as well as the duration of diabetes mellitus, blood glucose concentration and glycated hemoglobin concentration. We performed a comparative analysis of the prognostic capabilities of this model with the sum of clinical and laboratory data of the patient history without the genetic aspect (Fig. 6, Table 6).

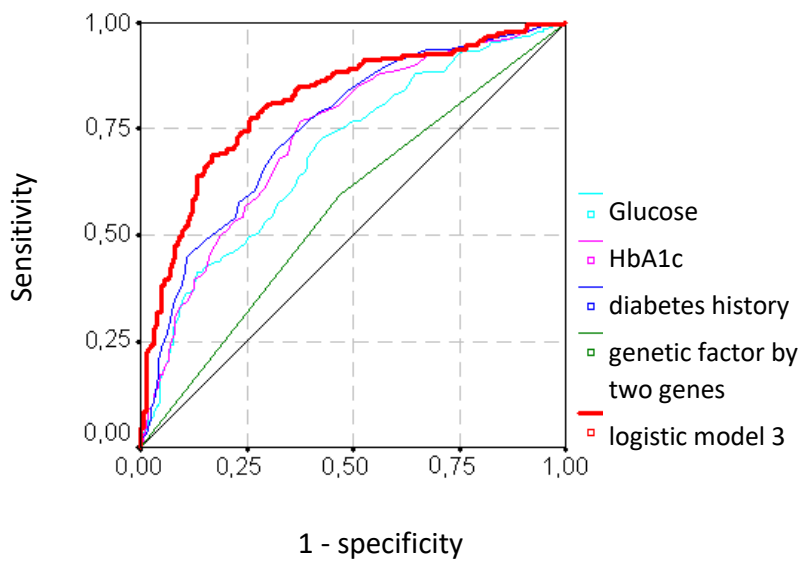

Figure 5. Ruc analysis of the third logistic regression model

Table 5. ROC analysis of the third logistic regression model

\begin{tabular}{|c|c|c|c|c|c|}
\hline \multirow[t]{2}{*}{$\begin{array}{l}\text { Test Result } \\
\text { Variable(s) }\end{array}$} & \multirow[t]{2}{*}{ Area } & \multirow[t]{2}{*}{$\begin{array}{l}\text { Std. } \\
\text { Error(a) }\end{array}$} & \multirow[t]{2}{*}{$\begin{array}{l}\text { Asymptotic } \\
\text { Sig.(b) }\end{array}$} & \multicolumn{2}{|c|}{$\begin{array}{l}\text { Asymptotic } \\
95 \% \\
\text { Confidence } \\
\text { Interval }\end{array}$} \\
\hline & & & & $\begin{array}{l}\text { Lower } \\
\text { Bound }\end{array}$ & $\begin{array}{l}\text { Upper } \\
\text { Bound }\end{array}$ \\
\hline Logistic model 3 & 0.814 & 0.021 & $<0.001$ & 0.774 & 0.855 \\
\hline $\begin{array}{l}\text { Combination of } 2 \\
\text { gene genotypes } \\
\text { (VEGF; AKR1B1) }\end{array}$ & 0.562 & 0.027 & 0.024 & 0.509 & 0.615 \\
\hline Diabetes history & 0.752 & 0.023 & $<0.001$ & 0.708 & 0.797 \\
\hline $\begin{array}{l}\text { Glycated } \\
\text { hemoglobin \% }\end{array}$ & 0.734 & 0.023 & $<0.001$ & 0.688 & 0.780 \\
\hline Glucose & 0.692 & 0.025 & $<0.001$ & 0.643 & 0.741 \\
\hline
\end{tabular}

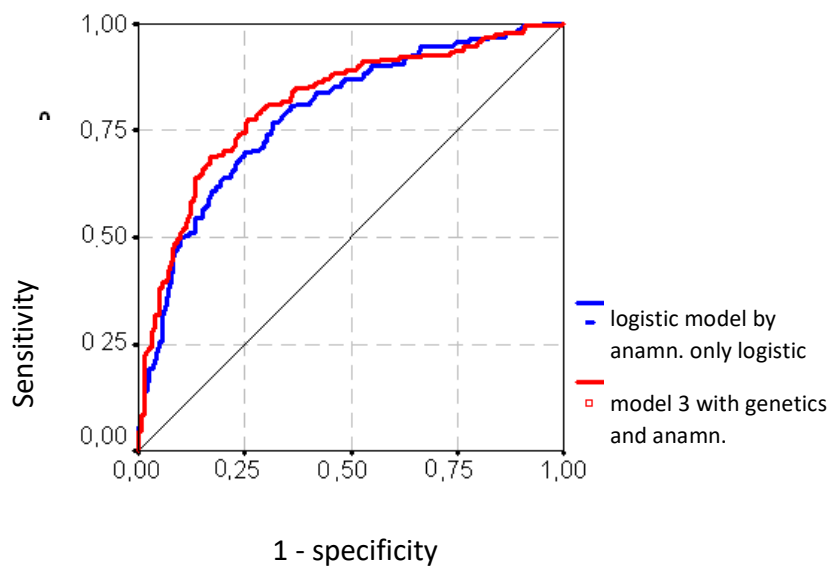

Figure 6. Comparative ROC analysis of the third logistic regression model with pooled clinical and laboratory history data 
Table 6. Comparative ROC analysis of the third logistic regression model with pooled clinical and laboratory history data

\begin{tabular}{|c|c|c|c|c|c|}
\hline \multirow{2}{*}{$\begin{array}{l}\text { Test Result } \\
\text { Variable(s) }\end{array}$} & \multirow{2}{*}{$\begin{array}{l}\text { Area AUC - } \\
\text { area under } \\
\text { the } \\
\text { schedule }\end{array}$} & \multirow[b]{2}{*}{$\begin{array}{l}\text { Std. } \\
\text { Error(a) }\end{array}$} & \multirow[b]{2}{*}{ p } & \multicolumn{2}{|c|}{$\begin{array}{l}\text { Asymptotic } \\
95 \% \\
\text { Confidence } \\
\text { Interval }\end{array}$} \\
\hline & & & & $\begin{array}{l}\text { Lower } \\
\text { Bound }\end{array}$ & $\begin{array}{l}\text { Upper } \\
\text { Bound }\end{array}$ \\
\hline $\begin{array}{l}\text { Combination } \\
\text { of } 2 \\
\text { genotypes } \\
\text { (VEGF; } \\
\text { AKR1B1) }\end{array}$ & 0.814 & 0.021 & $<0.001$ & 0.774 & 0.855 \\
\hline $\begin{array}{l}\text { Combination } \\
\text { of blood } \\
\text { glucose } \\
\text { concentration } \\
\text { and history of } \\
\text { diabetes } \\
\text { mellitus }\end{array}$ & 0.789 & 0.021 & $<0.001$ & 0.747 & 0.831 \\
\hline
\end{tabular}

According to the data presented in the table, we can see that model 3 including genetic factors has an area slightly larger (by 0.025) than the model with only the aggregate of clinical and laboratory data of the patient history (0.814 and 0.789). This difference in the performance is not large, but it is statistically significant. That supports the idea that diabetes mellitus duration, blood glucose concentration, and glycated hemoglobin are important indicators, but genetic factors also contribute to the development of diabetic retinopathy.

\section{DISCUSSION}

Of the candidate genes examined, three - VEGF, AKR1B1, and APOE - were associated with an increased risk of diabetic retinopathy. VEGF is a signaling protein produced by cells to stimulate vasculogenesis and angiogenesis. Overexpression of VEGF can cause vascular disease of certain parts of the body, particularly the retina. Foreign scientists have shown the influence of VEGF expression on the probability of DR in diabetes mellitus in many studies. They are Balasubbu S. et al., Paine S. K. et al. when studying the effect of this gene expression on the Indian population; Shahin R.M.H. et al. - when studying the effect of this gene expression on the Egyptian population. Memariani T. et al. studied the effect of this gene expression on the Iranian population; Buraczynska M. et al. studied the effect of this gene expression on the
Polish population [7]. However, in order to implement genetic screening, the frequency of mutations in the VEGF gene in the Russian multinational population should be studied.

AKR1B1 is an enzyme involved in glucose metabolism and osmoregulation, plays a protective role against toxic aldehydes, and plays an important role in many complications of DM, particularly retinopathy.

APOE is the gene encoding serum apolipoprotein E, which is part of chylomicrons and very low-density lipoproteins. About 14 percent of the variation in plasma cholesterol levels can be attributed to variability in the APOE gene.

The combined clinical and genetic logistic model of selected candidate genes, biochemical parameters (glycated hemoglobin, glucose), and diabetes history increases the sensitivity and specificity of the test system up to $74 \%$. Note that the influence of genetic factors on the risk of diabetic retinopathy is higher than the values of biochemical, ophthalmological indicators [10].

Most studies provide sufficient evidence for the influence of a genetic factor on the development of diabetic retinopathy, but the involvement of each of the noted candidate genes for diabetic retinopathy is ambiguous. Researchers are inclined to believe that there is a correlation between the association genes and the ethnicity of the control group.

\section{CONCLUSION}

As a result of the research, the authors of the paper have come to the following conclusions. First, the polymorphic loci of VEGF rs2010963, AKR1B1 rs759853, ITGA2 rs2910964, ADRB3 rs4994, APOE rs7412, APOE 429358, considered independently of each other, were not associated with the development of diabetic retinopathy in the studied group of type II diabetic patients. However, consideration of complex interallelic interactions of VEGF, AKR1B1 and APOE genes allows us to identify unfavorable combinations of genotypes. Second, the age of diabetes and glycemia increase the likelihood of diabetic retinopathy. The proposed combination of genes in combination with biochemical indices increases the prognostic significance of the developed test system.

\section{REFERENCES}

[1] Yu.S. Bakhareva, O.D. Rymar, N.N. Chapaeva, Hemodynamic, biochemical, inflammatory, growth factors in patients with type 2 diabetes and preclinical diabetic nephropathy, Treatm. and prevent. 2 (2016) 77-83. 
[2] P.A. Bezdetko, Drug therapy of diabetic retinopathy at the stages of its development (problems, doubts, solutions), Ophthalmol. East. Eur. 1(28) (2016) 109-123.

[3] Y.S. Astakhov, F.E. Shadrichev, A.B. Lisochkina, Diabetic retinopathy (the tactics of patient management), Clin. Ophthalmol. 2 (2004) 85-88.

[4] L.I. Balashevich, A.S. Izmailov, Diabetic ophthalmopathy, Chelovek, Saint Petersburg, 2012.

[5] P.B. Velichko, E.M. Osmanov, Modern methodological approaches to the treatment of diabetic retinopathy, TSU Bull. 18(6) (2013) 32483249.

[6] I.V. Vorobyeva, D.A. Merkushenkova, Diabetic retinopathy in patients with type 2 diabetes mellitus. Epidemiology, modern view of pathogenesis, Review, Ophthalmol. 9(4) (2012) 18-21.

[7] N.A. Ermakova, Diabetic retinopathy. Clinic, diagnosis, classification, treatment, Clin. Ophthalmol. 1 (2013) 33.

[8] A.G. Iskhakova et al., Analysis of mutation frequency of genes associated with diabetic retinopathy in the Volga population, Modern probl. of sci. and ed. 6 (2019). Retrieved from: http://scienceeducation.ru/ru/article/view?id=29283

[9] L.W. Hahn, M.D. Ritchie, J.H. Moore, Multifactor dimensionality reduction software for detecting gene-gene and gene-environment interactions, Bioinformat. 19(3) (2003) 376-382.

[10] D. Jusufbegovic, M.O. Mugavin, S. Schaal, Evolution of controlling diabetic retinopathy: changing trends in the management of diabetic macular edema at a single institution over the past decade, Retina 35(5) (2015) 929-934. 